\title{
Urban sustainability and individual behaviour
}

\author{
D. Müller-Eie \& L. Bjørnø \\ Department of Industrial Economics, Risk Management and Planning, \\ University of Stavanger, Norway
}

\begin{abstract}
This paper supports an understanding of individual behaviour as an inherent part of a holistic approach to implementing urban sustainability. Based on this premise, the types of behaviour that are associated with the implementation of urban sustainability are highlighted. Challenging the tacit assumption that behaviour can be changed by merely changing policy and the built environment, an expanded view of behaviour change is proposed. This includes a literature study of other relevant disciplines investigating key factors that impact on individual decisionmaking, which are categorised as socio-cultural, demographic and psychological. Also, the importance of habitual behaviour as mitigating factor for behaviour change is discussed.

In conclusion, a schematic model of the individual's role in decision-making and thus on urban sustainability realisation is proposed. The purpose of this is to clarify the duality between provision and use of urban sustainability strategies. As such, this paper constitutes preliminary work to the development of a holistic and integrated theory and research framework for the implementation of urban sustainability taking into account infrastructure, policy, behaviour and other aspects.

Keywords: urban sustainability, individual behaviour, sustainable behaviour, behavioural change, adoption.
\end{abstract}

\section{Introduction}

This paper builds on a previously established model of the urban sustainability concept [1]. Fig. 1 shows urban sustainability viewed as a holistic concept that encompasses several arenas (global/abstract, local/concrete) as well as different actors. The figure also reveals that collective and individual behaviour is the subject of many urban sustainability strategies. Individual behaviour must 
therefore be understood as an integrated part of implementing urban sustainability strategies. It also becomes apparent that individual behaviour is governed by a variety of factors, such as demographic attributes, attitudes, lifestyles and the cultural environment.

Through a literature study of relevant theory we review the current perception and application of the concept of urban sustainability. Based on this we propose an increased focus on individual behaviour and which behaviours are most critical for successfully implementing urban sustainability. While external factors for individual decision making have previously been categorised as cultural and social [2], we deepen and extent this understanding to include psychological factors. In order to investigate factors and attributes that can influence decision making, existing models for individual decision making are reviewed.

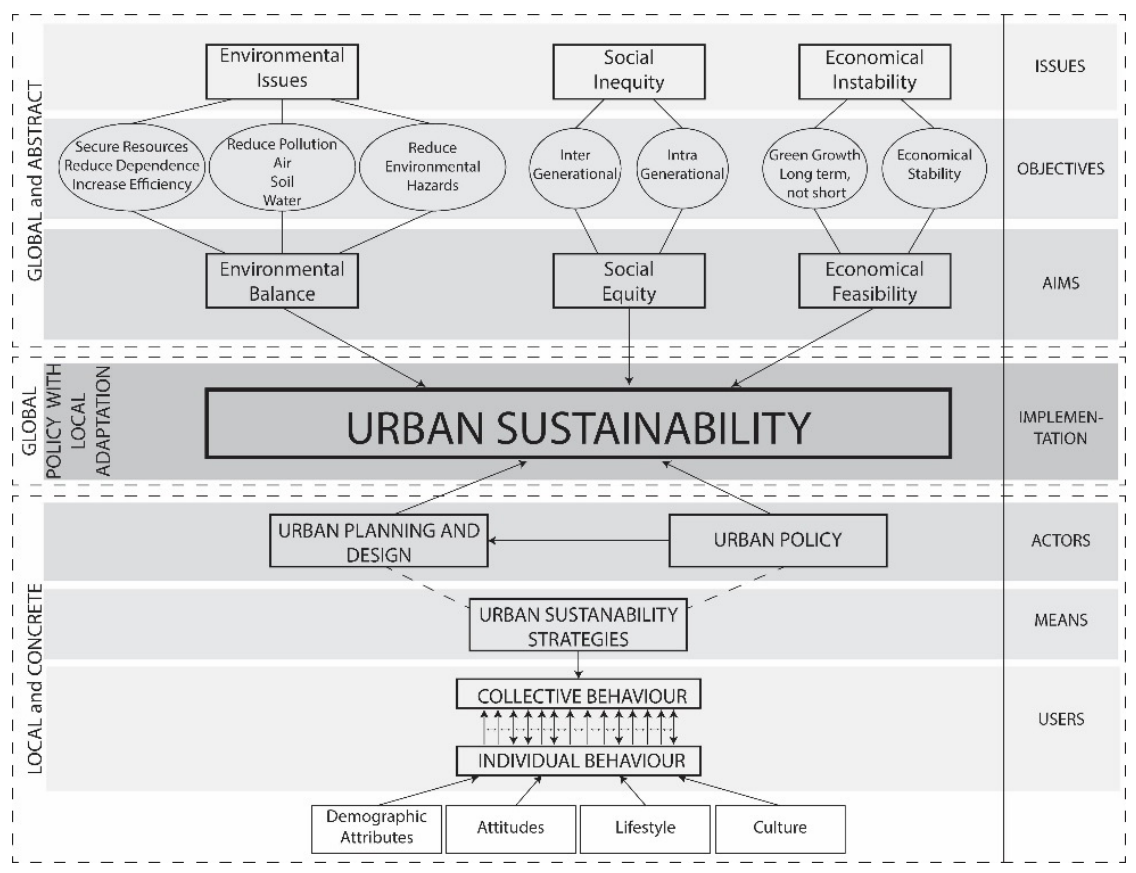

Figure 1: Urban sustainability as a set of concepts and sub-concepts [1].

Disciplines such as urban planning and design often operate under the tacit assumption that physical infrastructure and provision of services (in addition to policies) 'automatically' will have an impact on behaviour, i.e. moderate undesired behaviour towards desired behaviour. However, there is little evidence to support this provision-use correlation [3]. We therefore suggest a stronger awareness for the individual decision-making process, also in physical disciplines. To gain a better understanding of the factors that impact individual behaviour, we look towards model from communication theory and environmental psychology, acknowledging the need for a more anthropocentric approach to implementing 
urban sustainability strategies. While we acknowledge the obvious relevance and necessity for physical, infrastructural, functional and political provision as a prerequisite for successful urban sustainability implementation, this paper focuses on the user side, i.e. the individual and his or her decision-making processes within an urban setting.

From Fig. 1 we can also see that the realisation of the urban sustainability strategies can be divided into institutional-provisional (actors and means) and individual-behavioural actions (means and users). (Provisional here means regarding provision, supply and facilitation and will be used as such in this paper.) Urban institutions need to provide infrastructure and services and facilitate their use (through policy and incentives); urban individuals on the other hand need to actually choose to use the provided infrastructure, services and facilities, and change their behaviour accordingly. This paper focuses on the latter, resulting in a theoretical and methodological framework that integrates both physical, policy and behaviour aspects in order to holistically propose and assess future urban sustainability strategy implementation.

\section{Defining individual sustainable behaviour in an urban context}

By 'implementation of urban sustainability' we mean concrete actions taken to realise chosen urban sustainability strategies [2]. This points toward the fact that the implementation process depends on several different stakeholders: political instances, public institutions, private corporations - but also the urban population.

Reviewing some of the commonly proposed urban sustainability strategies (such as modal change, intensification, renewability, etc.) (Fig. 2), it becomes apparent that these strategies can be viewed as having an institutional (red) and an individual (green) aspects for realisation. While some behaviours happen seldom and have a long-term impact (e.g. choice of dwelling location, dwelling type and household size), others are repeated often and can therefore become habitual (travel behaviour, energy consumption, waste separation) (see section 3.4).

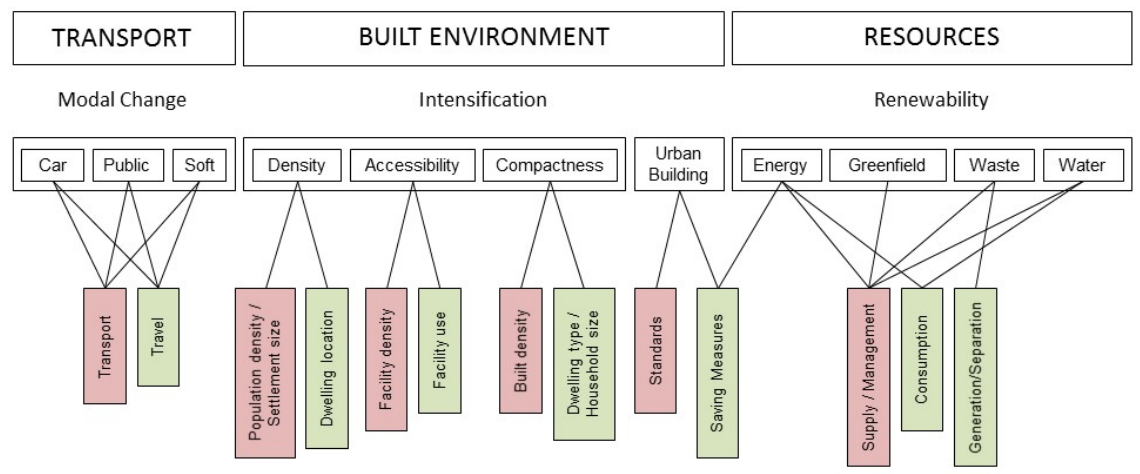

Figure 2: Urban sustainability strategies and their realisation [2]. 
In the following we will use modal change from car toward public transport as an example. For this change to be facilitated, institutions need to provide: 1) appropriate and accessible infrastructure for public transport, 2) frequent and relevant public transportation service, and 3) incentives against car use (road taxation, road toll, parking fees, parking restrictions) and in favour of public travel (affordable tickets). When these infrastructural and political factors are covered, then 4) the individual has to make the decision to use the provided infrastructure and travel by public means in order to fully implement the respective urban sustainability strategy. Based on this, we propose a dual approach, with provision of infrastructure (context) and policy on one side, and individual choice and collective behaviour (society) on the other.

In this decision-process (against the car and for public transport) several factors such as travel cost, duration, comfort, convenience, status, directness of journey, feeling of safety, etc. will influence the individuals' action. In the following we will give an overview of several relevant sets of factors.

\section{Factors for individual decision-making}

The following gives an overview of relevant factors for individual decisionmaking based on a literature study of relevant communication and environmental behaviour theories.

These reveal that the factors based on which people make choices are many, and they range from institutional provision, and social situation to cultural context. People might act based on convenience, financial restraints, out of habit or based on their values and beliefs. In other literature factors for behavioural choice are often categorised into practical/instrumental, normative/symbolic and hedonic/affective [4].

Despite the fact that these factors arguably overlap and depend on each other, this paper categorises factors impacting on the individual decision-making process into:

- individual cultural attributes: attitudes, values and beliefs that are impacted by society, community and culture;

- individual social attributes: measureable demographics that consciously or unconsciously impact decision-making;

- individual psychological attributes: emotions that govern decision making affectively.

Viewing the implementation process of sustainable behaviours from an individual point of view, in a previous publication [1] we argue that urban sustainability can be viewed as a social innovation according to Rogers [5]. He describes the adoption process in five stages: knowledge, persuasion (positive or negative attitude), decision (acceptance or rejection), implementation (use) and confirmation [5]. In the following we present the findings of the literature study structured according to this five-staged process since it offers a sound perspective of decision-making.

Providing the individual with knowledge about a technological or infrastructural innovation, or about the impact of their behaviour is important. In 
fact a linear progression between knowledge-awareness-behaviour has earlier been proposed in the Deficit model [6, 7]. However, this model was criticised for being an insufficient and inappropriate basis for policy making [6, 8], as well as assuming a direct link between attitudes and behaviour [9].

Persuasion as described by Rogers [5] is the process where the individual develops an attitude towards the respective technological or infrastructural innovation. Here not only the individuals' personal attributes play a role, but also the social and cultural environment in which the individual lives. Therefore interpersonal approaches that target the community as well as the individual have been suggested $[6,8]$ (see section 3.1).

The decision making process, i.e. the acceptance or rejection of the introduced innovation is what is particularly relevant to this paper. This is where the individual develops a concrete response to given impulses, and where many other factors impact on the adoption of a certain behaviour (see section 3.2 and 3.3).

The implementation of the innovation manifests in the actual behaviour, e.g. the use of buss for work travel. This is traditionally what the implementation of a certain urban sustainability strategy can be measured in, e.g. public transport patronage.

The confirmation process is reflective and only happens after the innovation was accepted or rejected, e.g. choice of buss or car. This fifth stage is particularly important as it gives the adoption process a feedback loop that provides for possible change of the initially adopted attitude and decision.

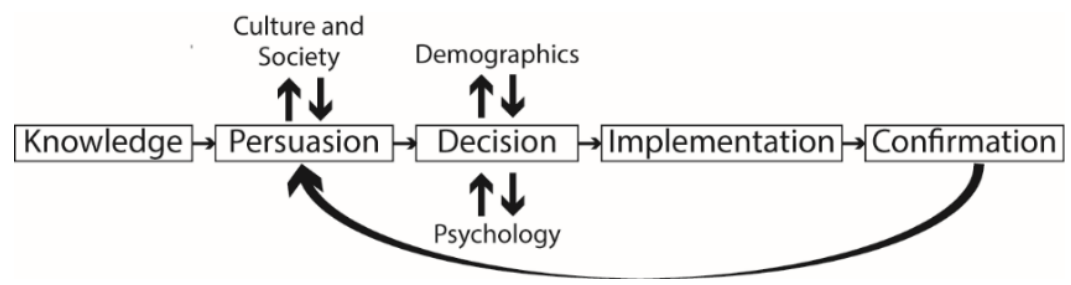

Figure 3: Adoption process adopted from [5].

Based on the above process description, we will first look at factors that play into the persuasion process, and second into the decision process.

\subsection{Individual socio-cultural attributes (attitudes, values, beliefs, norms) impacting on the persuasion process}

As mentioned above, attitudes can be the result of what Rogers [5] calls persuasion. This process is something that happens between the individual and his or her environment as well as within the individual. One category of factors that plays into this part of decision-making is the socio-cultural influence that individuals experience when interacting with their local community. Here, general ethics and moral play a fundamental role. Social norms, values and beliefs also help to form an attitude, which together constitute the basis for a positive or negative response to an innovation. 
This aspect of decision-making has also been referred to as normative [10] or symbolic $[4,6,11]$, because it is based on normative and moral considerations and feeds back into social identity. Whitmarsh and O'Neill [12] for instance describe the role of pro-environmental self-identity (i.e. a sense of self) on proenvironmental behaviour. The symbolic meaning of adopting a certain technology or displaying a certain behaviour can be interpreted as part of one's maturity, intelligence, awareness, agreeableness, conscientiousness and openness [4].

This way of decision-making is described in individual behavioural theories $[6,13]$ that take larger cultural and social influences into account, such as Norm Activation Theory [14] and Values-Beliefs-Norms Theory [15]. These theories describe the occurrence of altruistic behaviour based on people's concern for others, their awareness for consequences, their recognition of responsibility and, consequently, their moral obligation to protect common welfare [6]. Despite being models that discuss individual decision-making, they see the individual as part of a larger community that influences their behaviour.

Also, interpersonal and network theories such as Triandis Theory of Interpersonal Behaviour [16], Social Learning Theory [17] and Social Capital Theory [18] have been referred to in order to explain how individual actions are influenced by their relationships with others. Such sociological theories are grounded in the hypothesis that individual behavioural change is best achieved by addressing communities (social networks, social support groups, role models, mentors) [6]. Particularly, Social Learning Theory overlaps with Rogers [5] Diffusion of Innovation in so far as both theories place great meaning on observation of behaviour for learning.

One way to record individual's persuasion is through attitudes. An established way of recording attitudes is administering a questionnaire with attitude statements where respondents can rank their level of agreement on a Likert scale. However, attitudes might not be reliable predictors of actual behaviour (attitude-behaviour gap) $[6,19]$.

Awareness has been argued to be a relevant factor for attitudes [20,21], as well as the importance of certain attributes of the respective technology [20]. Gatersleben et al. [22] for instance point out that the perceived impact of one's behaviour will contribute to forming a negative or positive attitude. A feeling of influence (awareness of consequences) can lead to a sense of responsibility (ascription of responsibility), and can contribute positively to behaviour.

All these factors can contribute to what elsewhere has been called intention or motivation [4, 13, 23] to adopt a certain action. This might be reported in willingness to change behaviour. This indicator becomes particular important in the discussion about whether the pure knowledge or awareness about an action actually contributes to making a change [9, 24], like the Deficit Model would suggest $[6,8,9]$.

\subsection{Individual social attributes (socio-economic demographics) impacting on the decision process}

One of the most viable and obtainable social data in terms of empirical investigation is demographic information, such as gender, age, income, education, 
households size. These are personal attributes, while impersonal attributes such as employment rates and crime rates can also play a role. These variables have repeatedly been used to categorise user groups and relate to sustainable behaviour.

Gender has rarely been related to environmental behaviour [25]. However, a medium-sized relationship between gender and the distance between home and used facilities was detected, with women using facilities closer to home [2]. Age, as an attribute, might prove not to be directly related to behaviour, but might have indirect implications through its correlation with income. Thus, it has repeatedly been shown to relate to behaviour [2, 22, 25-27]. Household size has been related with domestic per capita energy consumption [20, 22, 25], and held the strongest explanatory power for water and energy consumption as well as negative dwelling and travel behaviour [2]. The level of income has also been shown to negatively relate to sustainable behaviour $[20,22,25,26,28]$. It has repeatedly been claimed that high income is one of the most adverse factors to overcome in implementing urban sustainability, since financial incentives are likely to have a lower effect in affluent populations [2]. A related variable, the level of education, can be seen to be positively related with income and might have a similar negative impact on behaviour [20,22]. This is despite assumed relationships between education and awareness. Employment is another variable relating to environmental behaviour [20-22, 25, 28].

Here, some of the instrumental aspects of decision-making become apparent; this means a rational evaluation of functionality, utility, performance and reliability [4]. Particularly purchase price and running cost will most likely be relevant in relationship to personal economy.

Decision-making theories such as the Rational Choice Theory and the Theory of Planned Behaviour [29] are based on the assumption that functional attributes, such as cost and benefit, play a decisive role. These theories assume that behaviour is based on rational and reasoned decisions, which engage cognitive facilities $[6,8,13]$. While this can be true for socio-economic aspects that govern an individuals' financial ability to use a certain service, it has been argued that other less rational factors also play into decision-making.

Thus, demographics have been readily applied and investigated in order to understand travel behaviour (e.g. in analysis and forecasting). However, Anable et al. [6] argue that "personal characteristics can explain increasingly minor variations" (p. 127), often show inconsistencies and that subjective aspects such as attitudes and values increasingly infiltrate such traditional investigations.

\subsection{Individual psychological attributes (emotions and affect) impacting on the decision process}

Another set of factors, possibly among the most decisive [23], consists of emotional responses to a new technology or innovation. Such emotional responses, also called affect, can be positive (pride, happiness, satisfaction, excitement, pleasure) or negative (fear, worries, anger, stress, boredom) [23, 30]. Other such affects can be guilt, embarrassment or pleasure (hedone) and these aspect are therefore often referred to as hedonic $[4,10]$. 
This is mainly based on Loewenstein and Lerner [31] and has been widely investigated [23]. Brannigan [32], for instance, says that behaviour is mainly governed by the pursuit of pleasure and the avoidance of fear.

The relevance of these individual and subjective aspects makes it difficult to develop strategies that respond to user groups, since for instance demographic groups are rarely homogenous in their psychological disposition. Particularly when the emotions stand in contrast to rational factors (i.e. 'public transport is cheaper but I feel unsafe using it'), individuals tend to decide in favour of their emotions - not reason [23]. It is therefore crucial to appeal to the avoidance of negative emotions as well as the achievement of positive emotions when introducing new technology or policy, in addition to appealing to rational aspects. Installing a sense of pride, ownership, security or pleasure in people can strongly contribute to them developing a positive attitude and action.

Here Brannigan [32] suggests slowing down the decision-making process so that the affect regulation (duality of emotions plus ratio) can bring non-conscious action into the conscious sphere and leave room for reflection.

In order to incorporate all of these barriers we will in the following discuss habits as a strong factor. The concluding proposal for a coherent framework for understanding and researching the change of behaviour in terms of urban sustainability will also incorporate social and situational factors (see section 4).

\subsection{Automated decisions: habitual behaviour}

All the above presented behavioural structures assume a conscious or nonconscious (but still cognitive) process of decision-making. However, some behaviours are not decided upon but have become automated, namely habits. "Habits are repeated behaviours that have become automatic responses in recurrent and stable context" [13, p. 22] and habitual behaviours are effortless [32]. This applies for instance to travel behaviour, which is rarely deliberated and often based on routines. For habits, past behaviour is the best predictor of future behaviour [13, 19]. Verplanken [13], therefore, suggests that changing attitude in order to change behaviour might not be effective in habitual behaviour. A better strategy might be changing the behaviour first (e.g. through legislation, taxation, infrastructure, availability of products, etc.) and adapt attitudes later on. It is also suggested that a situational change (moving, job shift, change in living situation, etc.) are favourable conditions for discontinuing habits [13]. To an extent, this might also be true for the introduction of new infrastructure which impacts on individual routines. It is therefore suggested that the implementation of new infrastructure and polices is accommodated by strong focus on individual behaviour and the possibilities to change it [33].

Schwanen et al. [34] on the other hand argue for the need to reframe the common understanding of habits away from an "automatically cued, repetitive behaviour of individuals" and toward a "generative and propulsive capacity brought about by repetition and belonging to the body-mind-world assemblages" (p. 305). They among other propose increased focus on positive habit formation as well as habit breaking and see habits as capacities. From this it becomes 
apparent that there is a need to research and better understand habitual (travel) behaviour in order to be able to facilitate behavioural change.

\section{Toward an integrated approach}

The purpose of this literature study of factors for individual behavior and its relevance to urban sustainability implementation, is to gain a better understanding of the realisation process and the mechanisms in place for individuals changing their behavior from carbon-intensive toward more sustainable.

Wall [35] proposes a combination of the Norm Activation Theory, ValueBeliefs-Norm Theory, the Theory of Planned Behavior as well as affective evaluations (freedom, status), symbolic evaluations (self-identity) and habits. Huijts et al. [23] on the other hand assert that "no comprehensive framework for sustainable energy technology acceptance has yet been proposed" (p. 526). The same is true with regards for sustainable urban behavior in general. While Huijts et al. [23] conclude with a schematic model of the technology adoption process, we attempt to develop an integrated approach combining the behavioural model with aspects of provision. The purpose of such a coherent model is to be able to better understand and research the implementation process of urban sustainability strategies.

The presented ideas can be summarised in a schematic model of the individual decision making process as defined by cultural and normative-symbolic, demographic and instrumental, and psychological and affective-hedonic factors (Fig. 4). We have further pointed out the attitude-behaviour gap and suggest that while pro-environmental attitudes are a precursor of sustainable behaviour, they are not the only predictor. And sometimes - as in the case of habitual behaviour they might not be relevant at all.

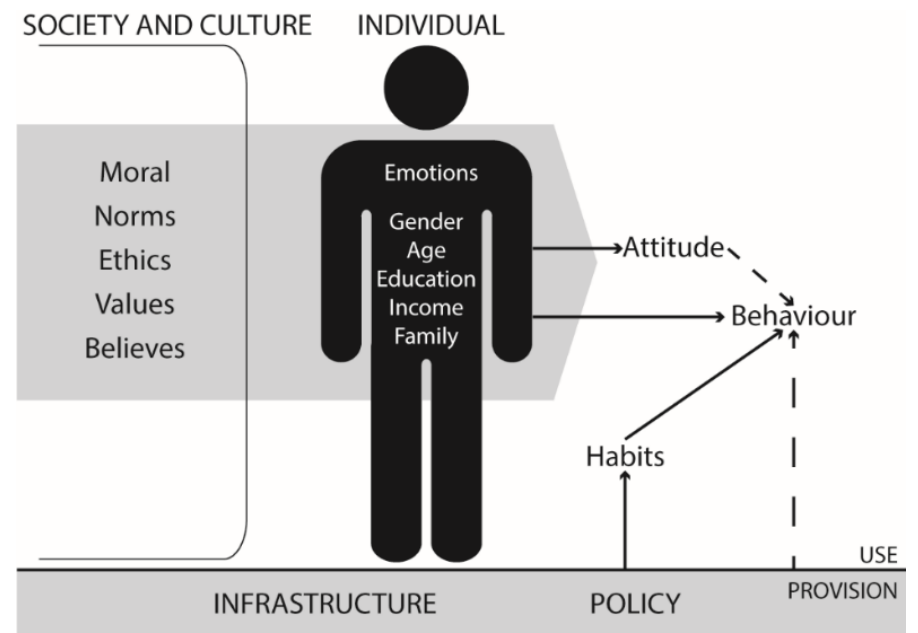

Figure 4: Individual decision making process based on community, context (provision and policy) and personal attributes (authors). 
The above presented review informs a holistic research framework that can contribute to understanding and investigating concrete strategies. This preliminary model will also help to develop a research framework [33]. Here individual choice will be treated as one part of a dual process of implementation (provision and use). This comprehensive framework can inform both theoretical approaches to urban sustainability as well as improve the development of urban sustainability strategies. In addition, this dual approach has relevance for developing a more holistic monitoring and assessment methodology for urban sustainability strategies. We therefore hope to spark new research approaches that investigate the success and failure of real-life examples.

\section{References}

[1] Müller-Eie, D. and L. Bjørnø. Urban Sustainability as Social Innovation. in THE SUSTAINABLE CITY IX Urban Regeneration and Sustainability. 2014. Sienna: WIT Press.

[2] Müller-Eie, D., Urban Environmental Performance and Individual Behaviour: A Comparison between Freiburg and Stavanger, in Glasgow School of Art: Mackintosh School of Architecture. 2012, University of Glasgow: Glasgow.

[3] Williams, K., C. Dair, and M. Lindsay, Neighbourhood Design and Sustainable Lifestyles, in Dimensions of the Sustainable City 2, M. Jenks and C. Jones, Editors. 2010, Springer: Dordrecht.

[4] Schuitema, G., et al., The role of instrumental, hedonic and symbolic attributes in the intention to adopt electric vehicles. Transportation Research Part A: Policy and Practice, 2013. 48(0): pp. 39-49.

[5] Rogers, E.M., Diffusion and Innovation. 5th ed. 2003, New York: Free Press.

[6] Anable, J., B. Lane, and T. Kelay, An Evidence Based Review of Public Attitudes to Climate Change and Transport Behaviour. 2006, The Department for Transport.

[7] Burgess, J., C.M. Harrison, and P. Filius, Environmental communication and the cultural politics of environmental citizenship. 1998.

[8] Whitmarsh, L., S. O'Neill, and I. Lorenzoni, eds. Engaging the public with climate change: behaviour change and communication. 2014, Earthscan: London.

[9] Owens, S. and L. Drifill, How to Change Attitudes and Behaviours in the Context of Energy. Energy Policy, 2008. 36: pp. 4415-4418.

[10] Lindenberg, S. and L. Steg, Normative, Gain and Hedonic Goal Frames Guiding Environmental Behavior. Journal of Social Issues, 2007. 63(1): pp. 117-137.

[11] Steg, L., Car use: lust and must. Instrumental, symbolic and affective motives for car use. Transportation Research Part A: Policy and Practice, 2005. 39(2-3): pp. 147-162.

[12] Whitmarsh, L. and S. O'Neill, Green identity, green living? The role of pro-environmental self-identity in determining consistency across diverse 
pro-environmental behaviours. Journal of Environmental Psychology, 2010. 30(3): pp. 305-314.

[13] Verplanken, B., Old habits and New Routes to Sustainable Behaviour, in Engaging the Public with Climate Change: Behaviour Change and Communication, L. Whitmarsh, S. O’Neill, and I. Lorenzoni, Editors. 2011, Earthscan: London.

[14] Schwartz, S.H., Normative influences on altruism. Advances in experimental social psychology, 1977. 10: pp. 221-279.

[15] Stern, P.C., et al., A value-belief-norm theory of support for social movements: The case of environmentalism. Human ecology review, 1999. 6(2): pp. 81-98.

[16] Triandis, H.C., Interpersonal behavior. 1977: Brooks/Cole Publishing Company Monterey, CA.

[17] Bandura, A. and D.C. McClelland, Social learning theory. 1977.

[18] Bourdieu, P., The forms of capital. (1986). Cultural theory: An anthology, 2011: pp. 81-93.

[19] Lane, B. and S. Potter, The adoption of cleaner vehicles in the UK: exploring the consumer attitude-action gap. Journal of Cleaner Production, 2007. 15(11-12): pp. 1085-1092.

[20] Ornetzeder, M., et al., The environmental effect of car-free housing: A case in Vienna. Ecological Economics, 2007. 65: pp. 516-530.

[21] Dieleman, F. and M. Wegener, Compact City and Urban Sprawl. Built Environment, 2004. 30(4): pp. 308-332.

[22] Gatersleben, B., L. Steg, and C. Vlek, Measurement and Determinants of Environmentally Significant Behaviour. Environment and Behaviour, 2002. 34: p. 335.

[23] Huijts, N.M.A., E.J.E. Molin, and L. Steg, Psychological factors influencing sustainable energy technology acceptance: A review-based comprehensive framework. Renewable and Sustainable Energy Reviews, 2012. 16(1): pp. 525-531.

[24] Næss, P., Central dimensions in a Sustainable Urban Development. Sustainable Development, 1995. 3: pp. 120-129.

[25] Stead, D., J. Williams, and H. Titheridge, Land Use, Transport and People: Identifying the Connections, in Achieving Sustainable Urban Form, K. Williams, E. Burton, and M. Jenks, Editors. 2000, E \& FN Spon: London.

[26] Weber, C. and A. Perrels, Modelling lifestyle effects on energy demand and related emissions. Energy Policy, 2000. 28: pp. 549-566.

[27] Larivière, I. and G. Lafrance, Modelling the electricity consumption of cities: effect of urban density. Energy Economics, 1999. 21: pp. 53-66.

[28] Druckman, A. and T. Jackson, Household Energy Consumption in the UK: A highly geographically and socio-economically disaggregated Model. Energy Policy, 2008. 36: pp. 3177-3192.

[29] Ajzen, I., The theory of planned behavior. Organizational behavior and human decision processes, 1991. 50(2): pp. 179-211.

[30] Anable, J. and B. Gatersleben, All work and no play? The role of instrumental and affective factors in work and leisure journeys by different 
travel modes. Transportation Research Part A: Policy and Practice, 2005. 39(2-3): pp. 163-181.

[31] Loewenstein, G. and J.S. Lerner, The role of affect in decision making. Handbook of affective science, 2003. 619(642): p. 3.

[32] Brannigan, F., Dismantling the Consumption-Happiness Myth: A Neuropsychological Perspective on the Mechanisms That Lock Us in to Unsustainable Consumption, in Engaging the Public with Climate Change: Behaviour Change and Communication, L. Whitmarsh, S. O'Neill, and I. Lorenzoni, Editors. 2011, Earthscan: London.

[33] Müller-Eie, D. and L. Bjørnø, The Implementation of Urban Sustainability Strategies: Theoretical and Methodological Implications for Researching Behaviour Change. 2015: Unpublished.

[34] Schwanen, T., D. Banister, and J. Anable, Rethinking habits and their role in behaviour change: the case of low-carbon mobility. Journal of Transport Geography, 2012. 24(0): pp. 522-532.

[35] Wall, R., Psychological and contextual influences on travel mode choice for commuting. 2006, De Montfort University. 